\title{
A multicentre, observational study of sodium picosulfate and magnesium citrate as a precolonoscopy bowel preparation
}

\author{
Jonathan Love $M D^{1}$, Edmond-Jean Bernard MD², Alan Cockeram MD³, Lawrence Cohen $\mathrm{MD}^{4}$, \\ Martin Fishman $\mathrm{MD}^{5}$, James Gray $\mathrm{MD}^{6}$, David Morgan $\mathrm{MD}^{7}$
}

J Love, E-J Bernard, A Cockeram, et al. A multicentre, observational study of sodium picosulfate and magnesium citrate as a precolonoscopy bowel preparation. Can J Gastroenterol 2009;23(10):706-710.

BACKGROUND: Sodium picosulfate with magnesium citrate (PSMC) has been available as a precolonoscopy bowel preparation in Canada since 2005. A high patient acceptability and preference appears to have contributed to its wide adoption across the country. Despite its frequent use, there are relatively few published studies of this product, especially reports regarding its use in routine clinical practice. Moreover, to date, there have been no Canadian studies of any kind.

OBJECTIVE: To conduct a preliminary evaluation of PSMC by prospectively collecting data describing its effectiveness.

METHODS: In the present multicentre, observational study, sequential patients used PSMC according to each institution's standard colonoscopy protocol. Differences in bowel cleansing protocols included dose timing, fluid intake, dietary restrictions and administration of bisacodyl. During colonoscopy, preparation quality was rated separately for the right and left sides of the colon.

RESULTS: Of the 613 patients entered, 606 were evaluable for efficacy. For the right and left colon, respectively, $93.0 \%$ and $96.2 \%$ of preparations were rated either 'excellent' or 'adequate'. In the 334 patients who received adjunctive bisacodyl and the 272 patients who did not, the results were similar: for the right and left colon, $92.3 \%$ and $97.1 \%$ of those who did not, and $93.4 \%$ and $95.7 \%$ of those who did receive bisacodyl, respectively, were rated either 'excellent' or 'adequate'. CONCLUSIONS: Despite the differences in bowel cleansing protocols used at each hospital (including an additional laxative), PSMC consistently yielded a high percentage of positive ratings for efficacy.

Key Words: Bowel preparation; Colonoscopy; Magnesium citrate; Sodium picosulfate

Tmportant barriers to performing successful colonoscopy are patient refusal to undergo the procedure and inadequate bowel preparation. In both cases, an important underlying cause is patient dislike or intolerance of the preparation (1). An alternative that offers greater tolerability and patient acceptance, and is safe and relatively inexpensive, is therefore, of interest to both endoscopists and patients.

One such alternative, that was introduced to the Canadian market in 2005, is sodium picosulfate with magnesium citrate (PSMC). This product has been in use for many years in the

\section{Étude d'observation multicentrique sur le picosulfate de sodium et le citrate de magnésium pour la préparation à la coloscopie}

HISTORIQUE : Le picosulfate de sodium avec citrate de magnésium
(PSCM) est offert au Canada depuis 2005 pour la préparation à la
coloscopie. Son emploi se serait répandu au pays parce qu'il est fort bien
accepté des patients qui lui accordent leur préférence. Malgré son
utilisation fréquente, relativement peu d'études ont été publiées au sujet
de ce produit, particulièrement en ce qui concerne son utilisation dans la
pratique clinique de routine. De plus, à ce jour, aucune étude n`a été
menée à son sujet au Canada. OBJECTIF : Réaliser une évaluation préliminaire du PSCM par le biais d'une collecte de données prospectives décrivant son efficacité.

MÉTHODE : Dans la présente étude d'observation multicentrique, des patients successifs ont utilisé le PSCM conformément au protocole standard établi pour la coloscopie dans leur établissement. Parmi les différences entre les divers protocoles de préparation du côlon, mentionnons le moment où le produit est pris, la prise de liquides, les restrictions alimentaires et l'administration de bisacodyl. Durant la coloscopie, la qualité de la préparation a été évaluée séparément pour le côlon droit et le côlon gauche.

RÉSULTATS : Parmi les 613 patients inscrits, 606 ont été jugés évaluables pour ce qui est de l'efficacité. Pour le côlon droit et le côlon gauche respectivement, 93,0 \% et 96,2\% des préparations ont été jugées soit « excellentes », soit « adéquates ». Entre les 334 patients qui ont reçu du bisacodyl comme mesure d'appoint et les 272 patients qui n'en ont pas pris, les résultats ont été similaires : pour le côlon droit et le côlon gauche, la préparation a été jugée soit « excellente », soit « adéquate » chez 92,3\% et $97,1 \%$ des sujets qui n'avaient pas pris de bisacodyl et chez $93,4 \%$ et $95,7 \%$ de ceux qui en avaient pris.

CONCLUSION : Malgré les différences quant aux protocoles de préparation du côlon appliqués dans chaque hôpital (y compris un laxatif additionnel), le PSCM a donné lieu, dans la plupart des cas, à un fort pourcentage de résultats positifs sur le plan de l'efficacité.

United Kingdom and other European countries, but Canadian clinicians have had less experience with PSMC than with other products such as sodium phosphate $(\mathrm{NaP})$ and polyethylene glycol (PEG), which have been in use in Canada for many years.

PSMC is a unique, orange-flavoured, dual-action purgative, dosed as two powder sachets that are mixed with water and typically taken several hours apart in combination with adequate hydration. The active ingredients include sodium picosulfate, magnesium oxide and citric acid. Once in solution, magnesium oxide and citric acid combine to form magnesium citrate, which

${ }^{1}$ Foothills Medical Centre, Calgary, Alberta; ${ }^{2}$ Centre Hospitalier de l'Université de Montréal, Montreal, Quebec; ${ }^{3}$ St John Regional Hospital,

St John, New Brunswick; ${ }^{4}$ Sunnybrook Health Sciences Centre, Toronto, Ontario; ${ }^{5}$ Richmond Hospital, Richmond; ${ }^{6}$ Vancouver General

Hospital, Vancouver, British Columbia; ${ }^{7}$ St Joseph's Healthcare, Hamilton, Ontario

Correspondence: Dr Jonathan Love, University of Calgary, 3280 Hospital Drive Northwest, Calgary, Alberta T2N 4N1.

Telephone 403-592-5017, fax 403-592-5090, e-mail jlove@ucalgary.ca

Received for publication January 23, 2008. Accepted January 22, 2009 
acts as an osmotic laxative, whereas sodium picosulfate acts as a stimulant laxative. In addition to its dual action, potential advantages of PSMC include relatively small volumes (each sachet is mixed with only $150 \mathrm{~mL}$ of water) and a more pleasant taste than current alternatives. Patients may be more likely to complete a preparation they find more tolerable, which can, in turn, positively impact efficacy.

In late 2006, the Canadian Association of Gastroenterology issued a position paper on bowel cleansing preparations currently used in Canada (2). The basis for the recommendations was a review of 50 published, randomized controlled trials involving various comparisons of primary and adjunctive bowel cleansing agents. Even more recently, a comprehensive systematic review of oral bowel preparations for colonoscopy that included 82 controlled trials, was published in Britain (3). Four comparisons of PSMC with other preparations were identified by both reviews, while the former review included two additional comparisons. These six studies produced equivocal results. PSMC showed equal efficacy to $\mathrm{NaP}$ (4), equal efficacy to PEG (5), superior efficacy to PEG (6), lower efficacy than $\mathrm{NaP}(7,8)$ and lower efficacy than PEG (9). In three of the six studies, the tolerability of PSMC was superior, and in the other three, it was found to be similar to that of the comparator. The authors of both reviews noted the relative paucity of head-to-head comparisons of PSMC with other preparations. Belsey et al (3) noted that small sample size contributed to inconsistent results among studies, precluding firm conclusions regarding relative efficacy, and that the various methods by which outcomes were determined further contributed to the inconsistency of the results.

Because there are no published Canadian data using PSMC, it was important to take steps toward formally accumulating and disseminating local PSMC experiences. Data relevant to bowel cleansing from seven centres across Canada were prospectively collected to assess the efficacy of PSMC in patients undergoing colonoscopy. For this preliminary assessment, efficacy was assessed using two scales: a 3-point qualitative scale and a semiquantitative 5 -point scale. Both were scored separately for the right and left colon, in recognition of the fact that the quality of bowel preparation frequently differs between colon segments.

The aims of the present study were to systematically assess the bowel cleansing efficacy of PSMC in a health care setting, and also to standardize and optimize the bowel cleansing regimen. This information may then serve to aid in the design of a future clinical study.

\section{METHODS}

At their respective institutions, which comprised four tertiary care and three community hospitals, each participating investigator approached patients who were to undergo colonoscopy regardless of age, sex or indication. Those who chose to participate in the study, received PSMC (Pico-Salax, Ferring Pharmaceuticals Canada) for precolonoscopy bowel preparation. Each institution's protocol for administration was followed, some of which included administration of bisacodyl. The various protocols differed with respect to dose timing, fluid intake and dietary restrictions; in all instances, patients were instructed to take two sachets of PSMC (see Appendix for a summary of the protocols for bowel cleansing with PSMC at each of the participating institutions).
TABLE 1

Patient enrollment

\begin{tabular}{lcc}
\hline & \multicolumn{2}{c}{ Patients, $\mathbf{~}$} \\
\cline { 2 - 3 } Site & Entered & Compliant \\
\hline 1 & 100 & 100 \\
2 & 100 & 99 \\
3 & 24 & 24 \\
4 & 105 & 103 \\
5 & 99 & 98 \\
6 & 91 & 88 \\
7 & 94 & 94 \\
All & 613 & 606 \\
\hline
\end{tabular}

*Took both sachets of sodium picosulfate with magnesium citrate as required

At colonoscopy, the right and left colon were scored separately for quality of preparation (eg, excellent, adequate or inadequate) to represent the investigator's overall assessment. A more specific rating used the following categories: clean/dry, clear liquid, murky liquid, adherent stool or full of stool. For this descriptive rating scale, in the few instances in which multiple categories were chosen to describe cleansing efficacy in a given bowel segment, the category lowest on the scale (ie, the 'worst' rating) was used in the data analyses. For example, if both 'murky liquid' and 'adherent stool' were selected, only the 'adherent stool' response was used.

Data were captured on standardized data collection forms and were entered into an Excel spreadsheet (Microsoft Corporation, USA). The data were summarized descriptively. Only compliant patients (ie, those who took the two required sachets of PSMC and no additional bowel preparations other than bisacodyl) were included in the data summaries. To determine the influence of bisacodyl administration on bowel preparation efficacy, data displays were prepared showing separate results for patients who used or did not use bisacodyl. Because of the sample size collected, no attempt was made to stratify the data with respect to other factors such as fluid intake, PSMC dose timing or dietary restrictions to correlate outcome with differences in bowel preparation protocol.

\section{Study population}

\section{RESULTS}

Between April 2006 and April 2007, 613 patients agreed to participate. Of these, 606 took both sachets of PSMC and were included in the data summaries (Table 1). Of the seven patients excluded from the analysis, five patients were excluded for taking less than the required amount of PSMC, one for taking both sachets and undergoing an $\mathrm{NaP}$ enema, and one for taking one sachet plus 30 tablets of bisacodyl. Results for the seven excluded patients ranged from inadequate to excellent.

The patients' mean $( \pm$ SD) age was $58.6 \pm 13.7$ years, with a range of 13 to 91 years. The majority of patients were women $(57 \%)$; at individual sites, the proportion of women ranged from $51 \%$ to $63 \%$.

\section{Quality of preparation}

Table 2 summarizes the distribution of overall assessment scores. The most frequent rating was 'excellent', which was lower for the right bowel than for the left $(53.4 \%$ versus $67.5 \%)$, while scores for an 'inadequate' rating were more frequent in the right than the left bowel $(7.0 \%$ versus $3.8 \%)$. Overall, for the right and left bowel, respectively, 93.0\% and $96.2 \%$ of preparations were rated either excellent or adequate. 
TABLE 2

Quality of bowel preparation: Overall assessment

\begin{tabular}{lcc}
\hline \multirow{2}{*}{ Rating } & \multicolumn{2}{c}{ Bowel, $\mathbf{n}(\%)$} \\
\cline { 2 - 3 } Excellent & Right $(\mathbf{n}=\mathbf{4 8 9})$ & Left $(\mathbf{n}=499)$ \\
Adequate & $261(53.4)$ & $337(67.5)$ \\
Inadequate & $194(39.7)$ & $143(28.7)$ \\
\hline
\end{tabular}

Site 4 inadvertently did not score quality of bowel preparation according to the excellent/adequate/inadequate scale for 90 of its 103 patients. Other sites occasionally missed scoring one or both sides

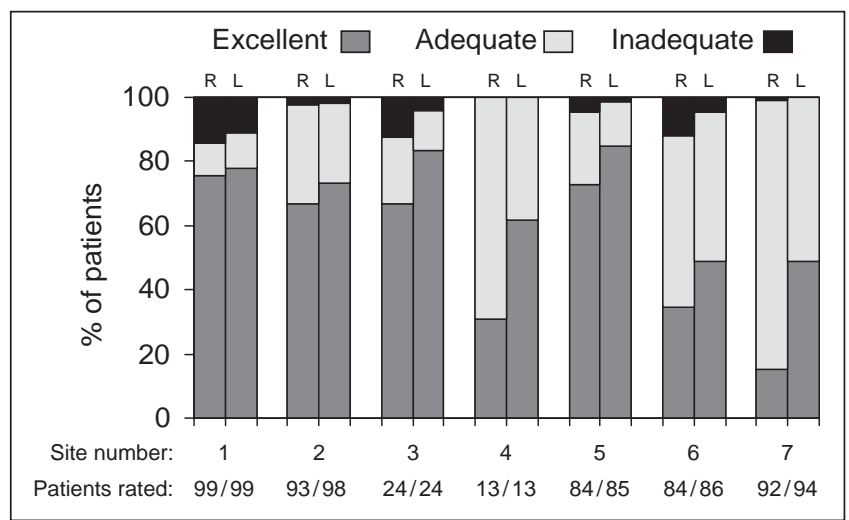

Figure 1) Overall quality of bowel preparation ratings according to site. Values $(x / y)$ shown for 'Patients rated' represent the number of patients rated for the right/left side of the colon, respectively. Site 4 inadvertently did not score quality of bowel preparation according to the excellent/adequate/inadequate scale for 90 of its 103 patients. Others sites occasionally missed scoring one or both sides. L Left colon; R Right colon

Figure 1 displays the bowel preparation quality scores according to participating site. Across sites, the scores were consistently better for the left colon than for the right colon. For the majority of patients at each site, the preparation quality for the left and right sides was scored as 'Excellent' (four sites), or as 'Excellent' and/or 'Adequate' (three sites).

Scoring of bowel preparation quality according to the presence of residual fecal matter is summarized in Table 3. Similar to the results of the 'excellent/adequate/inadequate' rating, the score distribution using this descriptive rating scale also shows poorer scores in the right than in the left bowel. A grouping of the descriptive responses was made as follows: clean/dry plus clear liquid, murky liquid, and adherent stool plus full of stool. Figure 2 displays the distribution of these grouped categories according to site. It is instructive to compare these data with Figure 1 in relation to the least satisfactory categories (ie, Figure 1 'inadequate' versus Figure 2 'adherent stool/full of stool'). There appears to be good correlation between the results shown in these two figures. A comparison of the right and left bowel, respectively, shows that $7.0 \%$ and $3.8 \%$ of preparations were rated 'inadequate', and $8.6 \%$ and $2.7 \%$ were graded 'adherent stool/full of stool'.

\section{Addition of bisacodyl}

To examine the influence of laxative use on preparation quality, the descriptive rating frequencies, with or without bisacodyl, including before, between and after the two sachets of PSMC, are presented in Figure 3. Administration of bisacodyl
TABLE 3

Quality of bowel preparation: Descriptive assessment

\begin{tabular}{lcc}
\hline & \multicolumn{2}{c}{ Bowel, $\mathbf{n}(\%)$} \\
\cline { 2 - 3 } Rating & Right $(\mathbf{n}=589)$ & Left $(\mathbf{n}=597)$ \\
\hline Clean/dry & $222(37.7)$ & $306(51.3)$ \\
Clear liquid & $138(23.4)$ & $166(27.8)$ \\
Murky liquid & $178(30.2)$ & $109(18.3)$ \\
Adherent stool & $48(8.1)$ & $13(2.2)$ \\
Full of stool & $3(0.5)$ & $3(0.5)$ \\
\hline
\end{tabular}

Some sites occasionally missed scoring one or both sides

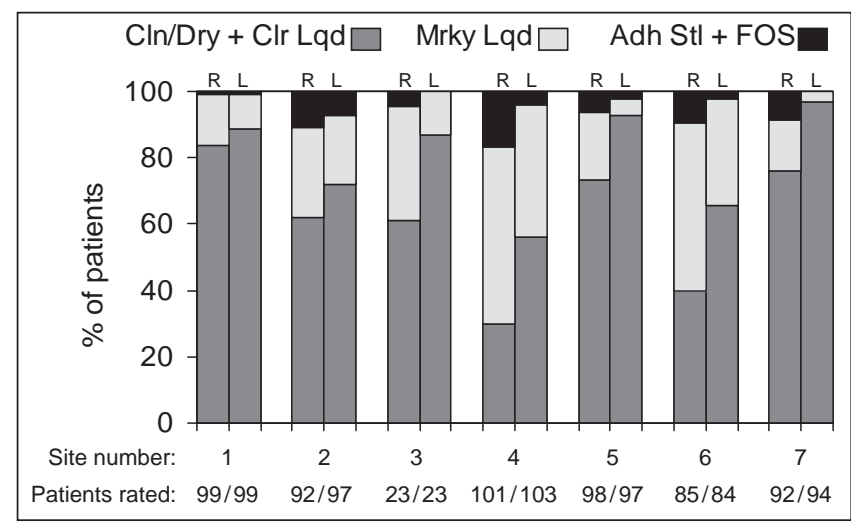

Figure 2) Overall descriptive quality of bowel preparation ratings according to site. Values $(x / y)$ shown for 'Patients rated' represent the number of patients rated for the right/left side of the colon, respectively. Some sites occasionally missed scoring one or both sides. Adh Stl Adherent stool; Cln/Dry Clean/dry; Clr Lqd Clear liquid; FOS Full of stool; L Left colon; Mrky Lqd Murky liquid; R Right colon

with PSMC, whether before, between or after the two sachets of PSMC, did not appear to produce more effective bowel cleansing than PSMC alone. In the overall assessment, among patients who received no bisacodyl, the preparation was scored as either 'excellent' or 'adequate' in $92.3 \%$ and $97.1 \%$ of patients for the right and left colon, respectively. Similar scores were observed among patients in whom bisacodyl was included as part of the bowel preparation: $93.4 \%$ and $95.7 \%$ were rated either 'excellent' or 'adequate' for the right and left colon, respectively (data not shown).

\section{DISCUSSION AND CONCLUSIONS}

We collected data on more than 600 patients who underwent colonoscopy and used PSMC as a bowel preparation. To reflect actual practice in Canada, each site followed its current bowel preparation protocol.

Inherent in observational research, such as in the present study, are the potentially confounding effects of intersite procedural differences. In particular, differences in time intervals between sachets of PSMC relative to the colonoscopy procedure, adjunctive laxative use, and dietary and hydration instructions may all contribute to variability in outcomes. In a controlled setting, for example, hydration instructions should specify volume, timing and type of allowable fluids. Despite the presence of these procedural differences, the results were fairly consistent across sites with respect to the general effectiveness of PSMC. 
Furthermore, even in the absence of a comparator, the overall data are consistent with previously published results (4-8).

However, the data must be interpreted cautiously because differences due to sites' bowel preparation practices cannot be distinguished from inter-rater variability in scoring. Moreover, the investigation was not designed or intended to definitively correlate procedures with bowel preparation effectiveness. We recognize that the scoring of the scales was relatively subjective and that ambiguity could have been avoided by using a validated scale. For example, when comparing Table 2 and Table 3, the overall ratings for 'inadequate' are similar to 'adherent stool/full of stool'. However, a visual comparison of Figure 1 and Figure 2 shows that same-site ratings for 'inadequate' and 'adherent stool/full of stool' varied across sites. In this case, factors such as the amount of stool present or the ease with which stool could be removed, would have affected the degree of visualization which, in turn, likely contributed to differences in observer ratings of 'Inadequate'.

With these caveats in mind, the evaluation of the quality of preparation stratified by bisacodyl use (yes/no) does not appear to indicate that the use of this stimulant laxative influenced the quality of bowel preparation. However, given the number of uncontrolled variables, the true role of adding a stimulant laxative such as bisacodyl warrants further study.

The findings of the present investigation, while interesting, remain to be confirmed in a randomized controlled trial. Ideally, such a trial would compare PSMC with other preparations, with the endoscopist blinded to the colonoscopy preparation used, and would use validated rating scales with good interobserver agreement and reliability, such as the Ottawa Bowel Preparation Scale 10. A full evaluation would include cost data, patient acceptance and tolerability assessments as secondary outcomes.

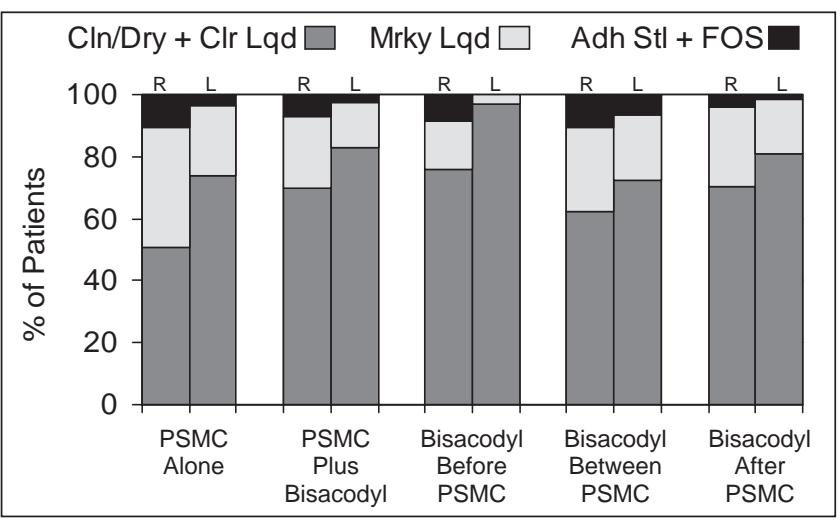

Figure 3) Descriptive quality of bowel preparation ratings with or without addition of bisacodyl. Sodium picosulfate and magnesium citrate (PSMC) plus bisacodyl includes administration of bisacodyl either before, between or after PSMC. Adh Stl Adherent stool; Cln/ Dry Clean/dry; Clr Lqd Clear liquid; FOS Full of stool; L Left colon; Mrky Lqd Murky liquid; R Right colon

\section{SUMMARY}

Despite differences in bowel cleansing protocols used at each hospital (including an additional laxative), PSMC consistently yielded a high percentage of positive ratings for efficacy.

ACKNOWLEDGEMENTS: The authors thank Sergio Dalla Nora (Ferring Pharmaceuticals) for data management and summarization, and Martha Watson for editorial assistance.

DISCLOSURE: The authors comprise the Ferring Pharmaceuticals Pico-Salax Advisory Board, and as such, have received honoraria for attending and contributing to advisory board meetings. However, they did not receive funding for the actual conduct of this investigation.

\section{APPENDIX}

Key features of bowel preparation protocols at study sites

\begin{tabular}{|c|c|c|c|c|}
\hline Site & Hydration* & Bisacodyl use & $\begin{array}{l}\text { Sodium picosulfate with magnesium } \\
\text { citrate (PSMC) interdose time interval }^{\dagger}\end{array}$ & Dietary restrictions \\
\hline 1 & $\begin{array}{l}250 \mathrm{~mL} / \mathrm{h} \text { after each sachet 'while } \\
\text { medication working' }\end{array}$ & All patients; after PSMC & 10 h (same day) & $\begin{array}{l}\text { Only clear fluids the day before the } \\
\text { procedure }\end{array}$ \\
\hline 2 & Abundant clear fluids emphasized & $\begin{array}{l}\text { All patients }{ }^{\ddagger} ; \text { between PSMC } \\
\text { sachets }\end{array}$ & 6 h (same day) & Not stated \\
\hline 3 & $\begin{array}{l}4 \text { large glasses following first } \\
\text { sachet, } 2 \text { to } 4 \text { glasses immediately } \\
\text { after second sachet }\end{array}$ & None $^{\S}$ & $12+\mathrm{h}$ (evening and next day) & $\begin{array}{l}\text { No grains or nuts for } 3 \text { days before } \\
\text { the procedure; only clear fluids the } \\
\text { day before the procedure }\end{array}$ \\
\hline 4 & $\begin{array}{l}1 \mathrm{~L} \text { to } 1.5 \mathrm{~L} \text { over } 4 \mathrm{~h} \text { after each } \\
\text { sachet, then } 250 \mathrm{~mL} / \mathrm{h} \text { 'while } \\
\text { medication working'. No fluids } \geq 3 \mathrm{~h} \\
\text { before the procedure }\end{array}$ & None & $\begin{array}{l}6 \mathrm{~h} \text { (same day) or } 10 \mathrm{~h} \text { (evening and } \\
\text { next day) }\end{array}$ & $\begin{array}{l}\text { Low-fibre diet for } 1 \text { week, avoid whole } \\
\text { grain breads and cereals, popcorn, } \\
\text { berries. Only clear fluids } 24 \mathrm{~h} \\
\text { before the procedure }\end{array}$ \\
\hline 5 & $\begin{array}{l}250 \mathrm{~mL} \text { per waking hour starting } \\
\text { the day before and up to time of } \\
\text { procedure }\end{array}$ & None & $6 \mathrm{~h}$ (same day) & $\begin{array}{l}\text { Low-fibre diet for } 1 \text { week, no whole } \\
\text { grain breads/cereals or fruits with } \\
\text { small seeds. Only clear fluids the day } \\
\text { before the procedure }\end{array}$ \\
\hline 6 & $\begin{array}{l}\text { 'Plenty of fluids'; no fluids after } \\
\text { midnight or } 4 \mathrm{~h} \text { preprocedure }\end{array}$ & $\begin{array}{l}\text { Variable } \pi \text {; if used, taken between } \\
20: 00 \text { and } 22: 00 \text { or } 4 \mathrm{~h} \\
\text { preprocedure }\end{array}$ & $6 \mathrm{~h}$ (same day) & $\begin{array}{l}\text { Only clear fluids the day before the } \\
\text { procedure }\end{array}$ \\
\hline 7 & $\begin{array}{l}\geq 1 \mathrm{~L} \text { after each sachet; no fluids } \\
\quad 4 \mathrm{~h} \text { before the procedure }\end{array}$ & All patients; before PSMC & 6 h (same day) & $\begin{array}{l}\text { Regular breakfast the day before the } \\
\text { procedure, only clear fluids thereafter }\end{array}$ \\
\hline
\end{tabular}

*Water or other clear fluid; 'Same day means both sachets taken the day before the procedure. Evening and next day means first sachet taken the day before, and the second sachet taken the same day as the procedure; ${ }^{\ddagger}$ Actual: 92 patients with bisacodyl taken between PSMC sachets (as per protocol); Seven patients with no bisacodyl taken; §Protocol specifies $30 \mathrm{~mL}$ 'Milk of Magnesia' (Bayer, USA) in the evening two days and one day before the procedure; 'Actual: 44 patients with no bisacodyl taken, 44 patients with bisacodyl taken after PSMC. Protocol also allows for preprocedure enema if preparation unsatisfactory 


\section{REFERENCES}

1. Harewood GC, Wiersema MJ, Melton LJ III. A prospective, controlled assessment of factors influencing acceptance of screening colonoscopy. Am J Gastroenterol 2002;97:3186-94.

2. Barkun A, Chiba N, Enns R, et al. Commonly used preparations for colonoscopy: Efficacy, tolerability and safety - a Canadian Association of Gastroenterology position paper. Can J Gastroenterol 2006;20:699-710

3. Belsey J, Epstein O, Heresbach D. Systematic review: Oral bowel preparation for colonoscopy. Aliment Pharmacol Ther 2007:25:373-84.

4. Schmidt LM, Williams P, King D, Perera D. Picoprep-3 is a superior colonoscopy preparation to Fleet: A randomized, controlled trial comparing the two bowel preparations. Dis Colon Rectum 2004:47:238-42.

5. Hamilton D, Mulcahy D, Walsh D, Farrelly C, Tormey WP, Watson G. Sodium picosulphate compared with polyethylene glycol solution for large bowel lavage: A prospective randomized trial. Br J Clin Pract 1996;50:73-5.
6. Regev A, Fraser G, Delpre G, et al. Comparison of two bowel preparations for colonoscopy: Sodium picosulphate with magnesium citrate versus sulphate-free polyethylene glycol lavage solution. Am J Gastroenterol 1998;93:1478-82.

7. Yoshioka K, Connolly AB, Ogunbiyi OA, Hasegawa H, Morton DG, Keighley MR. Randomized trial of oral sodium phosphate compared with oral sodium picosulphate (Picolax) for elective colorectal surgery and colonoscopy. Dig Surg 2000;17:66-70.

8. Tjandra JJ, Chan M, Tagkalidis PP. Oral sodium phosphate (Fleet) is a superior colonoscopy preparation to Picoprep (sodium picosulphate-based preparation). Dis Colon Rectum 2006;49:616-20.

9. Dakkak M, Aziz K, Bennett JR. Short report: Comparison of two orally administered bowel preparations for colonoscopy polyethylene glycol and sodium picosulphate. Aliment Pharmacol Ther 1992;6:513-9.

10. Rostom A, Jolicoeur E. Validation of a new scale for the assessment of bowel preparation quality. Gastrointest Endosc 2004;59:482-6. 


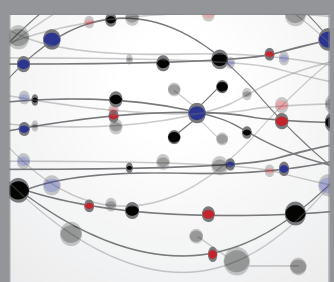

The Scientific World Journal
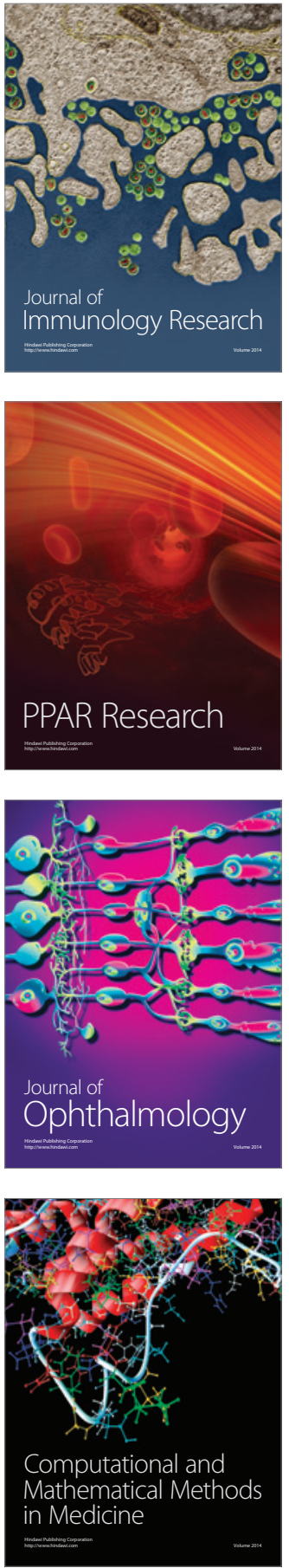

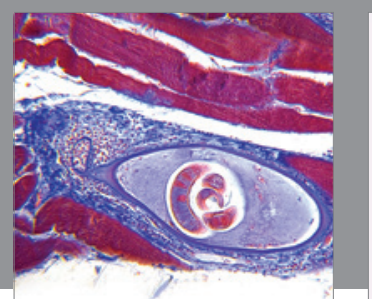

Gastroenterology Research and Practice

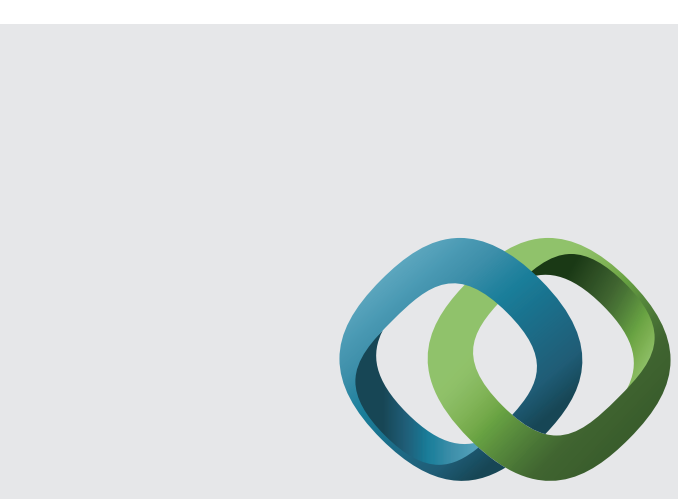

\section{Hindawi}

Submit your manuscripts at

http://www.hindawi.com
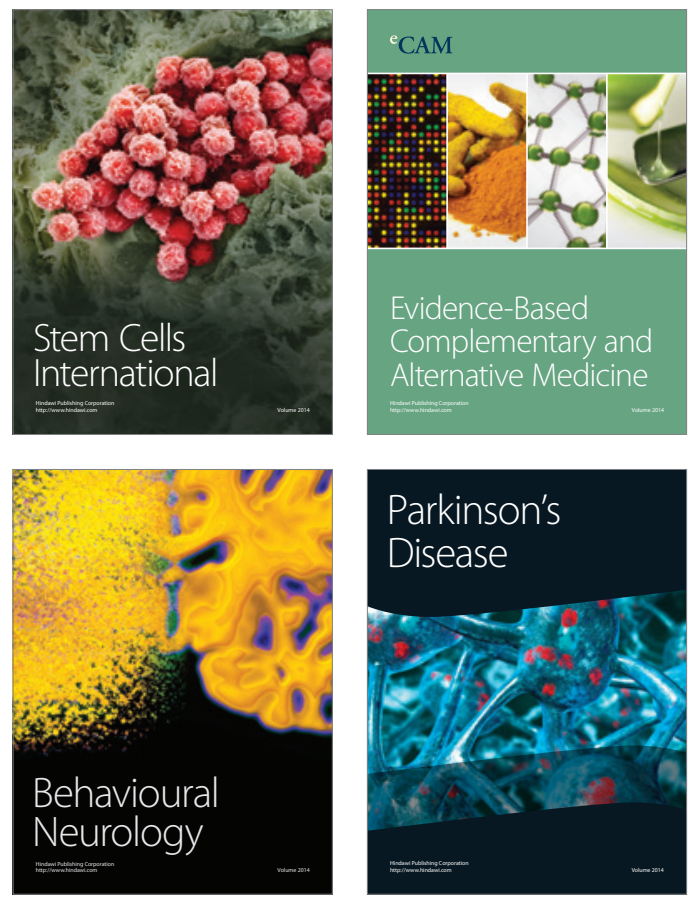
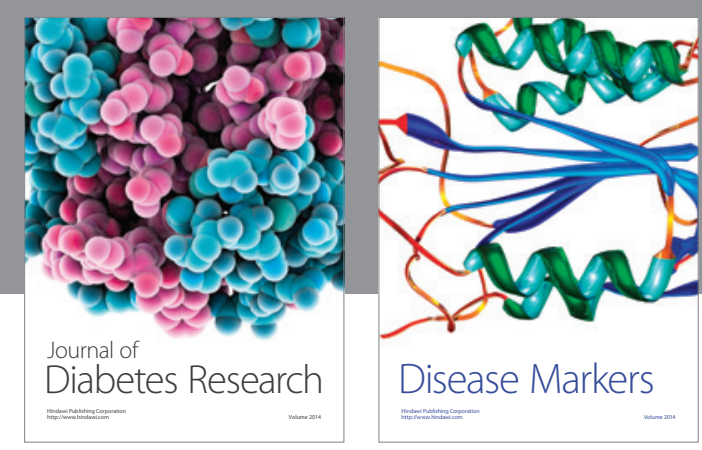

Disease Markers
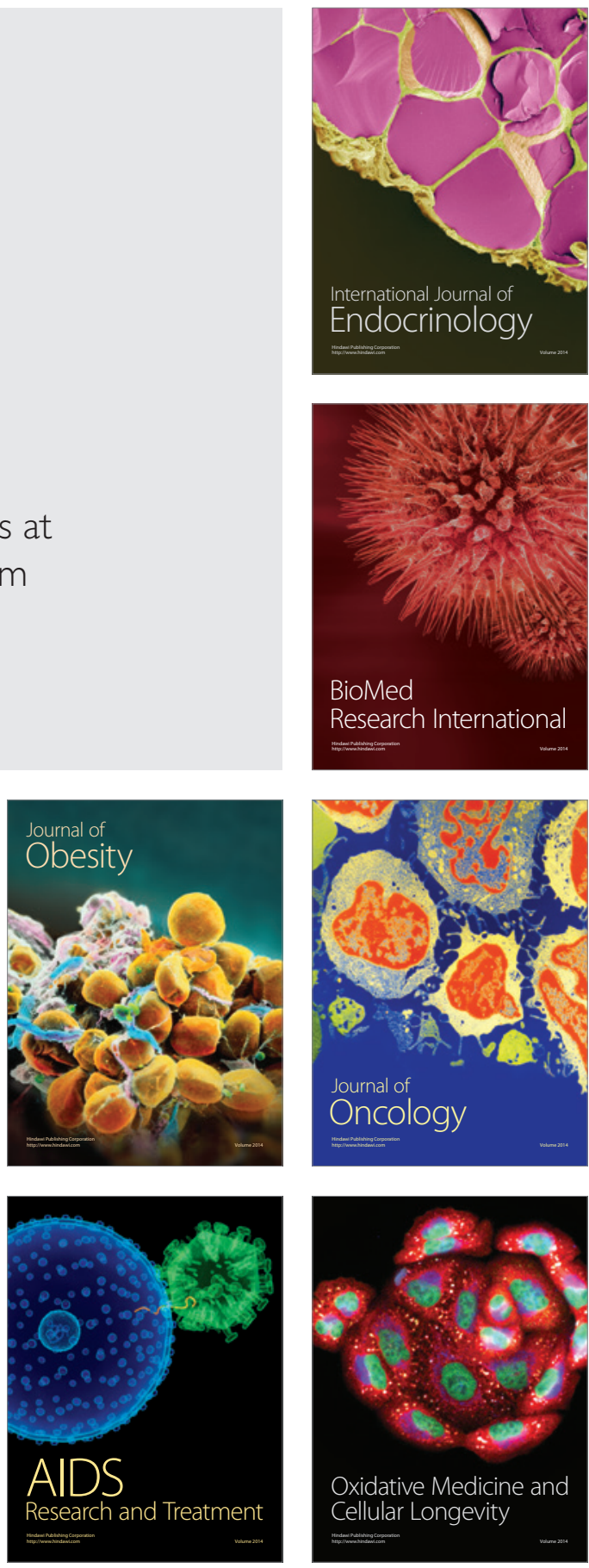